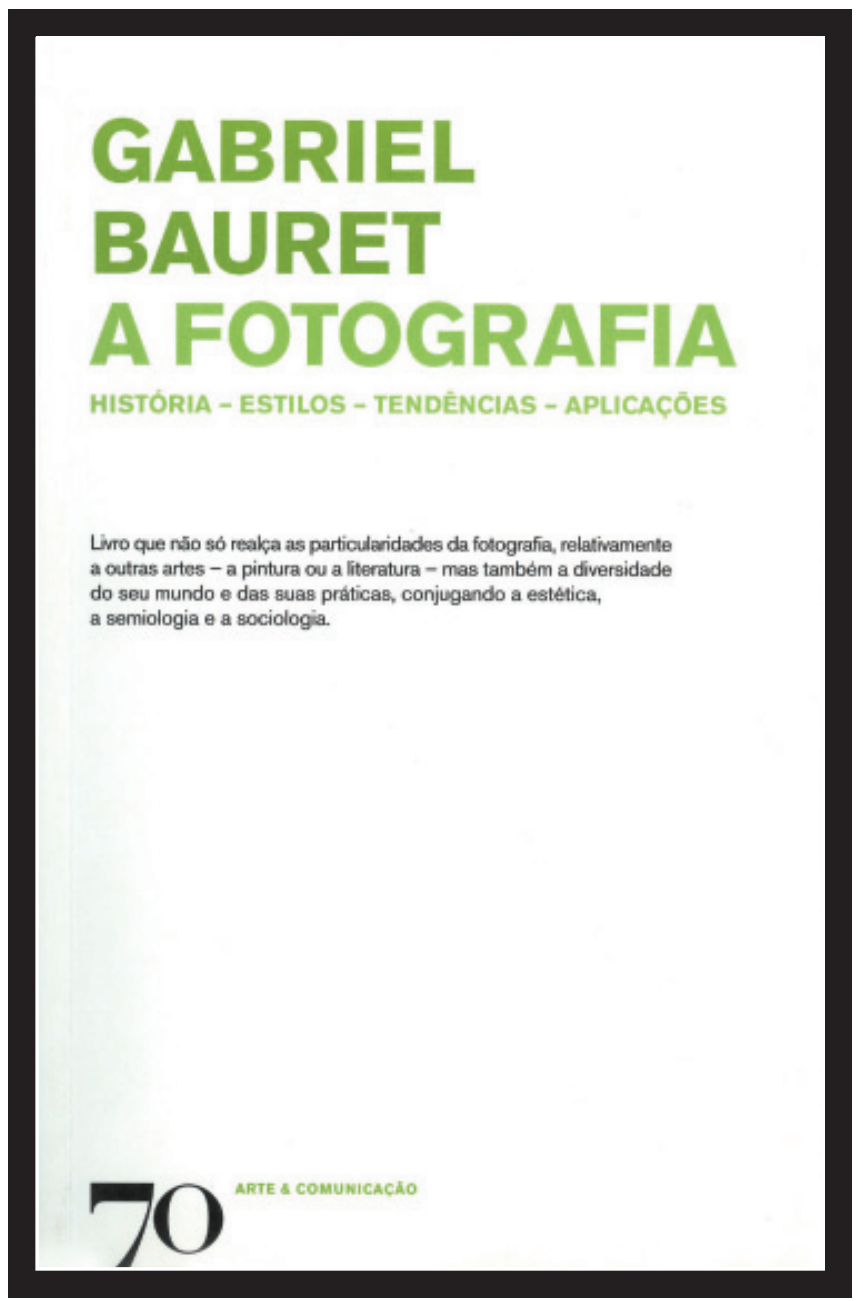

BAURET, Gabriel. Afotografia: história, estilos, tendências, aplicações. Lisboa: Edições 70, 2010, $136 p$. 


\title{
A fotografia: diversidade de abordagens em práticas diversas
}

Photography: diversity of approaches in different practices

\author{
TássiaRuiz*
}

Em 136 páginas de exposições concisas acerca das particularidades da fotografia, o livro A fotografia: história, estilos, tendências, aplicações, do fotógrafo parisiense Gabriel Bauret, conduz o leitor à diversidade de abordagens do mundo e das práticas fotográficas, não apenas segundo o ponto de vista histórico, mas também estético, sociológico e semiológico.

No século XIX, quando Nicéphore Niépce concebeu o problema da fixação da luz ao descobrir o princípio de formação das imagens na câmara escura, talvez não imaginasse que esse seria o ponto de partida para a diversidade de indagações, principalmente de caráter científico, que enfrentaram os primeiros fotógrafos em busca do aperfeiçoamento deste novo modo de criação visual que a fotografia inaugurou. O primeiro capítulo da obra A invenção da fotografia explora as circunstâncias e etapas da invenção da arte fotográfica, abordando seus progressos técnicos, os avanços em direção à iluminação artificial e a sensibilidade do suporte, que modificaram tanto a prática como a atitude do fotógrafo e sua temática; pois, liberto de limitantes técnicos, como a necessidade de longas e planejadas poses, pôde, segundo seu ponto de vista, tornar o tema sujeito a múltiplos olhares e manipulações.

Em A fotografia documental, segundo capítulo da obra, Gabriel Bauret percorre a evolução da função documental da exploração ao inventário e torna evidente o papel da fotografia como instrumento complementar à linguagem verbal. Ressalta as utilizações das fotografias, primeiramente nas explorações científicas pelo mundo, como instrumento

* Graduada em Design Gráfico pela Universidade Estadual de Londrina (UEL). Mestranda em Comunicação pela mesma instituição. Bolsista do CNPq. E-mail: ruiz.tassia@gmail.com 
exato e minucioso de descoberta e investigação de pesquisadores e, posteriormente, como registro histórico de grandes acontecimentos e de acervo do homem em sociedade, com suas práticas sociais e culturais. Ambas as práticas documentais exemplificadas assinalam o progresso da fotografia em relação a outras técnicas de ilustração, como em substituição ao caderno de esboços no caso das explorações científicas, principalmente pela particular relação que a fotografia apresenta com o real, "a escrita da luz", cujo testemunho de uma realidade é de tamanha credibilidade que se comparada com outras formas de representação, torna-se, neste aspecto, privilegiada.

Dentro da mídia, sua exploração enquanto documento marca a encomenda de sua realização e o agrupamento de fotógrafos em agências, como forma de defesa e estratégia de venda de seus trabalhos, exemplificada pela Magnum, agência fundada por Robert Capa, Henri Cartier-Bresson, George Rodger e David “Chim” Seymour, em 1947. O assunto é rediscutido no terceiro capítulo: Notas sobre alguns títulos $d a$ imprensa e algumas agências fotográficas, dedicado especialmente a alguns daqueles que se consagraram na história da fotografia, como o semanário francês $V u$, que, mesmo ainda não reconhecendo a autoria dos fotógrafos, foi o primeiro suporte do fotojornalismo moderno a tratar a fotografia como forma de expressão articulada com a linguagem verbal.

No entanto, o caráter ambíguo do instantâneo, principalmente como registro, não é esquecido. No quarto capítulo, Uma certa história do real, entra em debate a questão da objetividade do registro fotográfico, em que se destacam duas das abordagens do autor. A primeira trata a fotografia como um ponto de vista, registro de um instante decisivo do qual não haverá duas reações iguais. Logo, existem repórteres que procuram captar o instante mais representativo de um acontecimento, reivindicando o momento tal como foi; e há os que concebem a fotografia após longo e premeditado estudo, o que não condena manipular em favor de uma expressão mais estética. Uma segunda perspectiva sinaliza para os perigos por trás de uma aparente "objetividade", o poder da fotografia como formadora de opinião. Neste 
aspecto, relativo principalmente à mídia, situa a fotografia dentro de um processo que lapida segundo seus interesses uma mensagem, como um recorte e enquadramento de um original, que nunca será entregue ao público sem seu crivo, e que apoiado na verossimilhança da fotografia, torna-se perigosa ao reforçar a autenticidade de uma imagem encenada, de caráter fantasioso.

No domínio de $O$ retrato, quinto capítulo da obra, "a fotografia impôs-se de forma definitiva" (BAURET, 2010, p.56) como inventário de indivíduos ou de uma sociedade. Dois momentos marcam a evolução do gênero, de um registro que antes imortalizava altas personalidades por meio dos fotógrafos oficiais que eram capazes de sintetizar em uma imagem o simbolismo necessário para ilustrar a figura poderosa, até caírem na banalização, com sua produção intensiva e desordenada praticada por anônimos. As modificações nas condições de produção podem ter facilitado a tarefa de registro, que antes demandava tempo, o que pode fundamentar sua prática cada vez mais automatizada, espontânea e trivial enquanto documento, mas é preciso ressaltar a repercussão que tal acesso ao retrato causou à percepção humana, não apenas num sentido de olhar aguçado em relação ao mundo, mas na sensível evolução da percepção que o homem tem de si próprio, como a tomada de consciência da passagem do tempo.

Nos capítulos sexto e sétimo, partilhado entre fronteiras esfumadas, mas regidos por regras diferentes, o mundo da arte e o da encomenda são distinguidos. No mundo da arte aplicada, a moda e a publicidade conhecem na fotografia uma nova forma de representação de seus modelos e produtos. $\mathrm{O}$ mercado que antes contava com a manifestação do talento e da criatividade do fotógrafo para desenvolver ideias originais ou para reforçar a autenticidade de uma mensagem, na atualidade passa a atuar conforme as exigências de um mercado que é demasiado importante para experiências criativas de um artista. A complexidade do sistema envolvido na geração de uma imagem dificulta que uma mensagem tenha um criador. Sendo assim, grande parte dos fotógrafos torna-se anônima por trás da questão técnica, em razão de suas particularidades e competência. 
Embora o projeto da arte aplicada seja determinado pela encomenda, ou seja, não parte de uma particularidade do indivíduo, no mundo da expressão artística o projeto parece garantir maior liberdade à criatividade, procurando, ao contrário do fotógrafo publicitário, reivindicar a liberdade de criação e a autoria do fotógrafo.

A história da fotografia em sua progressiva busca pelo reconhecimento como forma de expressão é marco de uma sucessão de movimentos e estilos, como o pictorialismo, que vai contra a reprodução precisa da imagem, aproximando a fotografia cada vez mais das técnicas de domínio da pintura em contraste com a manifestação da straight photography (fotografia direta), movimento mais espontâneo que buscava uma revalorização do instante decisivo e essencialmente mais formal da arte fotográfica. $\mathrm{O}$ autor ainda se utiliza de um breve histórico sobe a revista Camera Work e seu idealizador Alfred Stieglitz, para ilustrar esta época de plena efervescência estética, como sendo a primeira revista a considerar a fotografia como um todo de expressão legítima.

Dando continuidade aos movimentos, Bauret aborda também a paradoxal relação entre o surrealismo e a fotografia - ou seja, entre o inconsciente e um processo de reprodução da realidade - e a Bauhaus, outra escola a ser comentada pelo seu processo experimental marcado pelo não habitual, pelo inédito e pelas combinações audaciosas. Finalmente, em tendências contemporâneas, marca-se o culto ao original, que vem na realidade contradizer uma arte que foi inventada para ser reproduzida, e passa a ser preocupação dos fotógrafos a realização de peças únicas cujo valor equivalesse aos das telas, como na fotomontagem. Há também os que recorriam à técnica fotográfica somente para fixar ideias, exaltando o artista pela sua inteligência e audácia, como Andy Warhol.

No último capítulo da obra, A fotografia: plural e singular, a argumentação que visa tratar o aspecto plural da fotografia baseia-se no contraponto entre a linguagem fotográfica e escrita. Jornalista e poeta, ambos escrevem, conforme o autor, mas, para tal, utilizam a palavra para a geração de sentidos diferenciados, isto porque ambos se dirigem a interpretantes diferentes, assim como o faz uma fotografia que deixa-se 
apropriar de múltiplas maneiras, seja pela estética, ciência ou sociologia. Qualquer que seja sua finalidade, sempre irá se submeter à releitura e recriação de uma existência por parte de cada leitor. Contudo, mantém sua singularidade, pois somente a fotografia pode mostrar pela sua particular maneira de fazer parar o tempo, de fixar um momento. O antes e o depois de um instante decisivo, que já desapareceu, uma ideia de morte que só a imagem fotográfica sabe produzir, a fim de ensinar uma nova maneira de observar o mundo, valorizando o pormenor, seja ele essencial ou banal.

Para o leitor interessado em fotografia, A fotografia, de Gabriel Bauret, é uma boa leitura para quem busca um relato objetivo, porém denso acerca da história e evolução fotográfica. Uma abordagem ricamente ilustrada de personagens e agentes da evolução fotográfica, que situarão o leitor na multiplicidade de seu mundo e sua prática, sem no entanto perder de vista sua singularidade enquanto meio privilegiado de representação da realidade, que mudou a forma como homem observa seu entorno e que se consagrou como forma de expressão artística. 